\title{
(2) OPEN ACCESS \\ Near-complete vision recovery from bilateral serous retinal detachment associated with thrombotic thrombocytopenic purpura
}

\author{
Tran Nguyen (1) , Saikripa M Radhakrishnan, Srinidhi J Radhakrishnan, \\ David H Johnson
}

Department of Internal Medicine, University of Texas Southwestern, Dallas, Texas, USA

\section{Correspondence to}

Dr Tran Nguyen;

trantnha.nguyen@gmail.com

Accepted 26 December 202

D Check for updates

(c) BMJ Publishing Group Limited 2022. Re-use permitted under CC BY-NC. No commercial re-use. See rights and permissions. Published by BMJ.

To cite: Nguyen T,

Radhakrishnan SM

Radhakrishnan SJ, et al. BMJ

Case Rep 2022:15:e244030.

doi:10.1136/bcr-2021

244030

\section{SUMMARY}

Ocular manifestations of thrombotic thrombocytopenic purpura (TTP) are uncommon, and bilateral retinal detachment is a rare presentation of TTP. We report a rare case of bilateral retinal detachment from underlying TTP in a patient presenting with vision loss. A 56-yearold man presented with a 4-day history of bilateral vision loss. Bilateral serous retinal detachment was confirmed using dilated ophthalmoscope examination. Laboratory results were significant for severe thrombocytopenia, peripheral smear revealed numerous schistocytes and ADAMTS13 activity of less than $1 \%$. The patient was treated with plasma exchange (PLEX), prednisone, rituximab and caplacizumab. This case report highlights that prompt treatment of TTP with PLEX, prednisone, rituximab and caplacizumab could result in significant vision recovery.

\section{BACKGROUND}

Thrombotic thrombocytopenic purpura (TTP) is a rare but life-threatening condition originally described in 1924 and characterised by the pentad of thrombocytopenia, microangiopathic haemolytic anaemia, neurologic symptoms, renal failure, and fever. ${ }^{1}$ The pentad of TTP is present in only $5 \%$ of patients. Moreover, presence of all of these signs indicates late presentation which is associated with high mortality and can be avoided with early diagnosis and prompt treatment. The dysregulation of von Willebrand (vWF)-dependent platelet adhesion causes microvascular thrombosis in multiple organs and is the feature of TTP. ${ }^{2}$ The common laboratory abnormalities include decreased platelet count, elevated lactate dehydrogenase, negative direct antiglobulin test and schistocytes on peripheral smears. Elevated creatine is seen with renal involvement. In contrast to disseminated intravascular coagulation, TTP has a normal coagulation panel. Furthermore, testing of ADAMTS13 levels will be abnormally low. The presence of thrombocytopenia and microangiopathic haemolytic anaemia and the absence of alternative causes should be treated empirically as TTP prior to the ADAMTS level resulting as its mortality exceeds $90 \%$ if left untreated. ${ }^{1}$

Ocular involvement is an uncommon manifestation of TTP, occurring in $14 \%-20 \%$ of patients reviewed. ${ }^{3-6}$ It is suspected that injury occurs from a combination of haemorrhagic and vaso-occlusive microangiopathy due to intravascular coagulation. Percival published the first case report of a patient who presented with bilateral exudative retinal detachment and TTP. ${ }^{6}$ Ocular manifestations of TTP were further delineated based on whether they are caused by more focal ocular lesions versus systemic microangiopathic involvement. ${ }^{46}$ The former category includes retinal detachment, choroidal bleeding and homonymous hemianopsia secondary to haemorrhagic lesions at the occipital poles. In the latter category, hypertensive retinopathy, chemosis, subconjunctival bleeding and retinal bleeding are associated with systemic manifestation of TTP. There are few case reports of bilateral retinal detachment as the initial manifestation of TTP. More commonly, retinal haemorrhages and serous macular degeneration were noted as primary ophthalmologic manifestation of TTP. ${ }^{3}{ }^{7-13}$ The wide range of reported vision complaints and variable ophthalmologic findings make TTP easy to overlook in the absence of additional systemic manifestations or laboratory evidence. To the best of our knowledge, we report the first case of TTP treated with plasma exchange (PLEX), prednisone, rituximab and caplacizumab with significant improvement of the patient's vision loss.

\section{CASE PRESENTATION}

A 56-year-old man presented with a 4-day history of bilateral vision loss, reported as curtains of red and black across his vision in both eyes. There were no other associated visual symptoms including ocular pain, focal weakness, recent illness or fever. He noted intermittent gum bleed while brushing his teeth for a few days prior to arrival. Other review of system was negative for mouth ulcers, joint pain, shortness of breath, hematochezia or melena or chest pain but was remarkable for a skin rash in the dorsal and ventral surfaces of both hands and hair loss of eyebrows and hairline for the past few months. His medical history was significant for hypertension and the recent diagnosis of biopsyproven psoriasiform dermatitis of his hands and scalp. His medications included amlodipine and triamcinolone ointment. He had a history of daily drinking (six beers/day) but denied history of any illicit drug use. Family history was negative for malignancy or autoimmune disease.

\section{INVESTIGATIONS}

The patient's vitals on presentation were notable for blood pressure of $153 / 88$ and heart rate of 104. Physical examination was remarkable for 
erythematous and eroded papules on bilateral dorsal and ventral hands. There was no evidence of mucosal bleed or purpura. Ophthalmology service was consulted for acute painless bilateral vision loss. Visual acuity test noted 20/200 in the left eye and $20 / 400$ in the right eye, with no improvement with correction or on pinhole testing. Intraocular pressure of the right eye by tonopen was $22 \mathrm{~mm} \mathrm{Hg}$ and that of the left eye was $24 \mathrm{~mm}$ $\mathrm{Hg}$. Anterior segment examination revealed conjunctival injection, $3+$ anterior chamber white blood cell and $1+$ flare consistent with intraocular inflammation in both eyes. In the fundus examination, they noted a cup-to-disc ratio of 0.5 , no oedema and yellow/white patchy subretinal lesions in the bilateral posterior pole, along with the presence of inferior subretinal fluid extending into the macula that exhibited a shifting pattern with patient positioning, suggestive of serous retinal detachment. There was absence of retinal holes, tears or breaks on peripheral examination. There were minimal cotton wool spots and intraretinal haemorrhages.

Laboratory studies were significant for platelets of less than $5\left(160-383 \times 10^{9} / \mathrm{L}\right)$, haemoglobin of $8.1 \mathrm{~g} / \mathrm{dL}$ with baseline haemoglobin of $12(13-17 \mathrm{~g} / \mathrm{dL})$, lactate dehydrogenase of 1018 (135-225 units/L), undetectable haptoglobin, total bilirubin of $3.7(0.2-1.3 \mathrm{mg} / \mathrm{dL})$ with indirect bilirubin of $1.2(0-0.3 \mathrm{mg} / \mathrm{dL})$ and international normalized ratio (INR) of 1.4. Rapid plasma reagin (RPR) was non-reactive. Peripheral smear had numerous schistocytes per high-power field. Creatine was $0.92 \mathrm{mg} / \mathrm{dL}$ with baseline of 0.64 . ADAMTS13 antibody was more than $104(\leq 15$ units $/ \mathrm{mL}$ ) and ADAMTS activity was less than 1\% (40-130\%). French Score was 2. Further work up revealed erythrocyte sedimentation rate (ESR) of $110(0-20 \mathrm{~mm} /$ hour), C-reactive protein (CRP) of $2.1(0-0.5 \mathrm{~mm} / \mathrm{dL})$, C3 level of $62(90-180 \mathrm{mg} /$ $\mathrm{dL})$, C4 level of $9(10-40 \mathrm{mg} / \mathrm{dL})$, negative antinuclear antibody, negative double stranded DNA antibody and anti-Smith antibody of 4.2 (0-0.9 AI). Additionally, human immunodeficiency virus antibody, hepatitis $\mathrm{B}$ surface antigen, and hepatitis $\mathrm{C}$ antibody were non-reactive. Vitamin $\mathrm{B}_{12}$ level was within range. Screen for malignancy with CT scan of the chest, abdomen and pelvis was unrevealing.

The patient's presentation was suggestive of lupus-related TTP given positive anti-Smith antibody, low complements, elevated ESR/CRP and rash consistent with subacute cutaneous lupus erythematosus versus discoid lupus.

\section{TREATMENT}

The patient was promptly started on prednisone $1 \mathrm{mg} / \mathrm{kg}$ and PLEX. He completed eight cycles of PLEX. Additionally, rituximab $375 \mathrm{mg} / \mathrm{m}^{2}$ was started on day 4 and given weekly for a total of four doses. Caplacizumab $11 \mathrm{mg}$ was given daily subcutaneously starting day 5, when his ADAMTS13 antibody came back positive, for a total of four doses due to slow platelet recovery. The patient was discharged after his platelet count improved to normal level. He did not require further treatment after finishing the fourth dose of rituximab at day 28 .

\section{OUTCOME AND FOLLOW-UP}

The patient had improvement in his vision starting from day 3 of hospitalisation. His platelet count was normal by day 8 (figure 1)

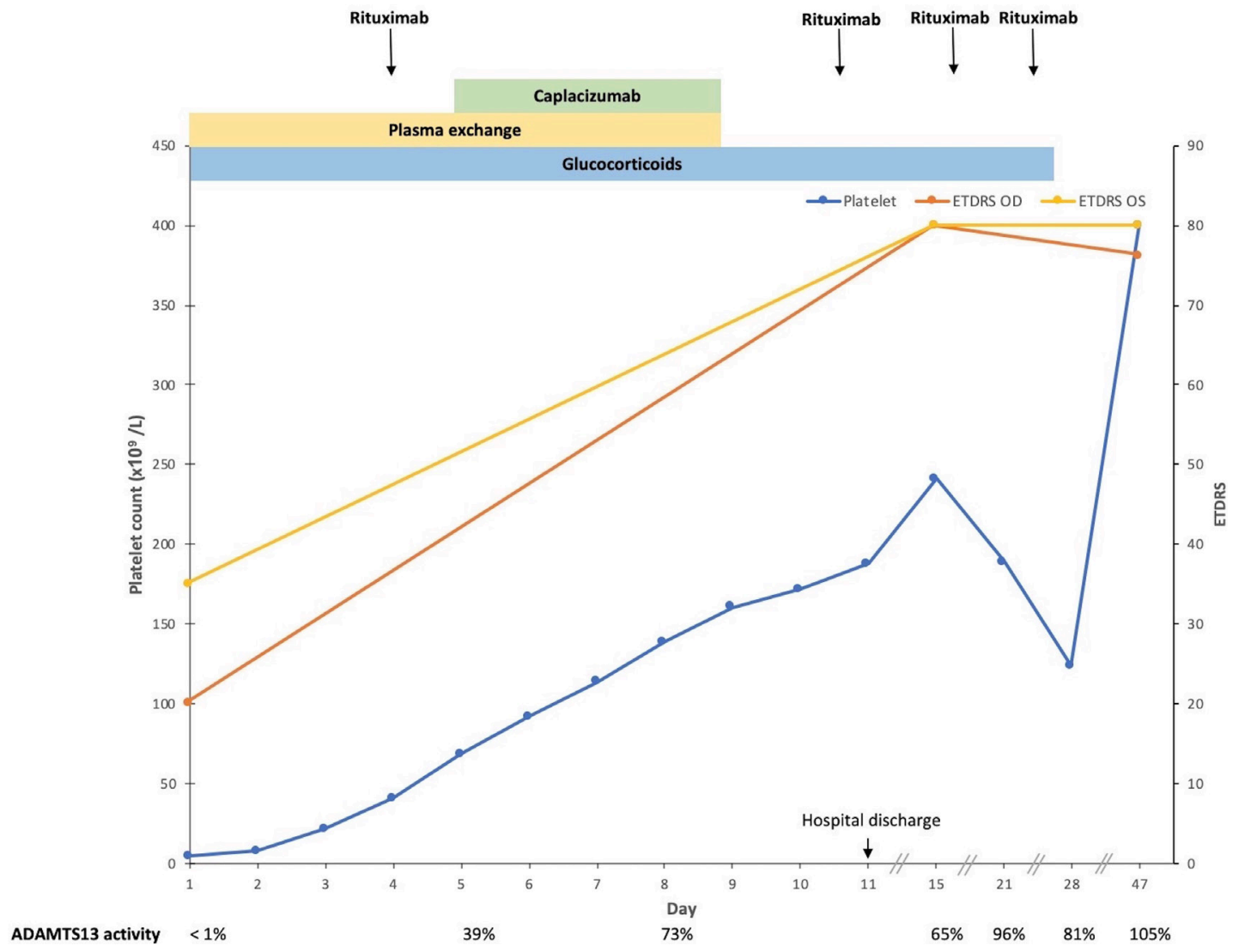

Figure 1 Treatment response. Response of platelet count (normal range 160-383×10 $/ \mathrm{L}$ ), Early Treatment Diabetic Retinopathy Study (ETDRS) chart and ADAMTS13 activity (normal range 40\%-130\%) are shown. Data are presented from day 1 of treatment (day of admission) to day 47. The patient received glucocorticoids (day 1 to day 28), plasma exchange (day 1 to day 8), rituximab (days 4, 11, 21 and 28) and caplacizumab (day 5 to day 8). $\mathrm{OD}$, right eye; OS, left eye. Authors will have permission to retain the image. 
and his creatine improved to baseline. Follow-up with ophthalmology demonstrated remarkable improvement of linear visual acuity to $20 / 25$ bilaterally on day 14 . Optical coherence tomography imaging of the macula demonstrated residual subretinal fluid in the subfoveal region of both eyes confirming bilateral serous retinal detachment. Fluorescein angiography indicated some patchy staining in the macula from residual inflammatory damage but no major dye leakage that would indicate vasculitis. Linear visual acuity in the right eye was 20/30 and in the left eye was $20 / 25$ on day 49 . The patient continued receiving outpatient care for his cutaneous lupus erythematosus.

\section{DISCUSSION}

In 1991, the TTP-associated mortality had reduced from 50\% to $22 \%$ with PLEX compared with plasma infusion. As such, PLEX has become the mainstay therapy for TTP. ${ }^{14} 15$ PLEX removes circulating antibodies and immune complexes from the patient's plasma. Within one study, out of 15 patients treated with PLEX, complete and lasting remission was noted in 9 instances. ${ }^{15}$ Additionally, rituximab, a chimeric mouse-human monoclonal antibody targeted against CD20, has also been used in the management of TTP. CD20 is a transmembrane protein found on B lymphocytes. Once rituximab binds to the CD20 ligand, it induces cell death by multiple modalities including antibody-dependent cell-mediated cytotoxicity, complementmediated cytotoxicity and apoptosis. It also works to rapidly reduce the production of antibodies thereby modulating CD4+ $\mathrm{T}$ lymphocytes and regulatory $\mathrm{T}$ cells. In a cohort study of UK patients, all 25 patients with refractory or relapsing TTP reached remission within 11 days of starting rituximab. ${ }^{16}$ Additionally, patients treated with rituximab had a quicker recovery of ADAMTS13 activity and reduced 1-year relapse rate. ${ }^{17}$ Hepatitis B status should be noted prior to administration of rituximab and lamivudine should be administered if hepatitis B is diagnosed.

A more recent development is the humanised single-variabledomain immunoglobulin caplacizumab, which inhibits the interaction between $\mathrm{vWF}$ multimers and platelets thereby preventing platelet activation and microvascular thrombosis. Patients who received subcutaneous caplacizumab during PLEX and for 30 days afterwards had a faster resolution of the acute TTP episode. However, these patients also had a higher bleeding risk. ${ }^{18}$

Review of case reports for patients with ocular TTP yielded varied treatment strategies and responses. One 46-year-old woman with recurrent TTP presented with sudden vision loss due to unilateral exudative retinal detachment received treatment with PLEX and steroids resulting in improvement in her vision symptoms starting at day $2 .{ }^{10}$ Another 32 -year-old woman with TTP-associated serous retinal detachment also achieved significant of visual acuity after 6 days of treatment with PLEX and steroids. ${ }^{19}$ Another case report noted a young female who developed bilateral serous retinal detachments from TTP that was treated with PLEX and rituximab, with improvement in vision from $20 / 400$ to $20 / 50$ in the span of 16 months. ${ }^{13}$ A paediatric patient who presented with orbital and nasal mucosal bleeding had improvement in the platelet count after three sessions of PLEX, but required 3 months for resolution of the ocular bleeding with long-term vision impairment. ${ }^{7}$ Lastly, a patient with bilateral vision loss due to occlusion of the central retinal artery and vein was monitored for 2 weeks after TTP treatment. Despite pan-retinal photocoagulation and transscleral cyclophotocoagulation, she did not regain meaningful visual function despite successful treatment of the underlying TTP. ${ }^{11}$
To the best of our knowledge, this is the first case report of TTP with ocular manifestations managed with caplacizumab alongside PLEX, corticosteroids and rituximab. Compared with previous reports in which only PLEX, corticosteroids and rituximab were given, the degree of visual recovery appeared favourable, with improvement noted within 2 days of initiating treatment and resolution within 1 month. In this case, prompt treatment with caplacizumab alongside PLEX, corticosteroids and rituximab might associate with speedy vision recovery. Further review of literature demonstrated two double, blind controlled trials using this regimen that showed a statistically significant reduction in TTP-related death, recurrence of TTP, treatment refractoriness and normalisation of organ-damage markers. ${ }^{20} 21$

\section{Learning points}

- While acquired thrombotic thrombocytopenic purpura (TTP) is idiopathic in approximately one-third of all cases, it can be associated with malignancy, autoimmune disease, pregnancy and drugs.

- Ocular TTP, including bilateral retinal detachment, is a rare but devastating manifestation of TTP. Therefore, TTP presenting with ocular manifestation can be overlooked in the absence of other systemic symptoms and supporting laboratory results.

- Management of TTP includes urgent plasma exchange, steroids and rituximab.

- The initiation of caplacizumab, in addition to the aforementioned therapies for TTP-associated ocular manifestation, might result in favourable outcomes with nearcomplete vision recovery.

\section{Twitter David H Johnson @dhjutsw1}

Acknowledgements The authors thank Kaden Andre, MD, for his review of the case and his ophthalmology expertise.

Contributors TN contributed to literature review. TN, SMR and SJR wrote the manuscript. All authors reviewed the manuscript and approved the submitted final version.

Funding The authors have not declared a specific grant for this research from any funding agency in the public, commercial or not-for-profit sectors.

Competing interests None declared.

Patient consent for publication Consent obtained directly from patient(s).

Provenance and peer review Not commissioned; externally peer reviewed.

Open access This is an open access article distributed in accordance with the Creative Commons Attribution Non Commercial (CC BY-NC 4.0) license, which permits others to distribute, remix, adapt, build upon this work non-commercially, and license their derivative works on different terms, provided the original work is properly cited and the use is non-commercial. See: http://creativecommons.org/ licenses/by-nc/4.0/.

Case reports provide a valuable learning resource for the scientific community and can indicate areas of interest for future research. They should not be used in isolation to guide treatment choices or public health policy.

\section{ORCID iD}

Tran Nguyen http://orcid.org/0000-0003-2611-317X

\section{REFERENCES}

1 Scully M, Hunt BJ, Benjamin S, et al. Guidelines on the diagnosis and management of thrombotic thrombocytopenic purpura and other thrombotic microangiopathies. $\mathrm{Br} J$ Haematol 2012;158:323-35.

2 Sadler JE. Pathophysiology of thrombotic thrombocytopenic purpura. Blood 2017;130:1181-8. 
3 Amorosi EL, Ultmann JE. Thrombotic thrombocytopenic purpura: report of 16 cases and review of the literature. Medicine 1966;45:139-60.

4 Bobbio-Pallavicini E, Porta C, Brocchieri A, et al. Ocular involvement in acute thrombotic thrombocytopenic purpura. Haematologica 1995;80:194-5.

5 Jellie HG, Gonder JR, Canny CL, et al. Ocular involvement in thrombotic thrombocytopenic purpura: the angiographic and histopathological features. Can J Ophthalmol 1984;19:279-83.

6 Percival SP. Ocular findings in thrombotic thrombocytopenic purpura (Moschcowitz's disease). Br J Ophthalmol 1970;54:73-8.

7 Agarwal A, Ram J. Pan-ocular hemorrhage in thrombotic thrombocytopenic purpura. Int J Hematol 2014;99:527-8.

8 Lambert SR, High KA, Cotlier E, et al. Serous retinal detachments in thrombotic thrombocytopenic purpura. Arch Ophthalmol 1985;103:1172-4.

9 Murphy PT, Rao P. Central retinal venous occlusion with co-existent thrombotic thrombocytopenic purpura and antiphospholipid syndrome. Br J Ophthalmol 2003;87:658-9.

10 Sampo M, Yin GHW, Hoffart L, et al. Exudative retinal detachment treatment in a patient with thrombotic thrombocytopenic purpura. Case Rep Ophthalmol 2016:7:90-5.

11 Schwartz SG, McPherson AR, Mieler WF, et al. Bilateral combined occlusion of the central retinal artery and vein secondary to thrombotic thrombocytopenic purpura. Arch Ophthalmol 2000;118:1304-5.

12 Stefani FH, Brandt F, Pielsticker K. Periarteritis nodosa and thrombotic thrombocytopenic purpura with serous retinal detachment in siblings. $\mathrm{Br} J$ Ophthalmol 1978;62:402-7
13 Williams PJ, Pearce WA, Smith JM, et al. Profound visual recovery at 16 months after resolution of serous retinal detachments secondary to thrombotic thrombocytopenic purpura: case report and literature review. Retin Cases Brief Rep 2021;15:18-21.

14 Rock GA, Shumak KH, Buskard NA, et al. Comparison of plasma exchange with plasma infusion in the treatment of thrombotic thrombocytopenic purpura. Canadian Apheresis Study Group. N Engl J Med 1991;325:393-7.

15 Bukowski RM, King JW, Hewlett JS. Plasmapheresis in the treatment of thrombotic thrombocytopenic purpura. Blood 1977;50:413-7.

16 Scully M. Rituximab in the treatment of TTP. Hematology 2012;17 Suppl 1:s22-4.

17 Froissart A, Buffet M, Veyradier A, et al. Efficacy and safety of first-line rituximab in severe, acquired thrombotic thrombocytopenic purpura with a suboptimal response to plasma exchange. experience of the French thrombotic microangiopathies reference center. Crit Care Med 2012;40:104-11.

18 Peyvandi F, Scully M, Kremer Hovinga JA, et al. Caplacizumab for acquired thrombotic thrombocytopenic purpura. N Engl J Med Overseas Ed 2016;374:511-22.

19 Titah C, Abisror N, Affortit A, et al. Bilateral serous detachment of retina: an unusual mode of revelation of thrombotic thrombocytopenic purpura of favorable outcome with plasma exchange. Graefes Arch Clin Exp Ophthalmol 2014;252:181-3.

20 Coppo P, Bubenheim M, Azoulay E, et al. A regimen with caplacizumab, immunosuppression, and plasma exchange prevents unfavorable outcomes in immune-mediated TTP. Blood 2021;137:733-42.

21 Scully M, Cataland SR, Peyvandi F, et al. Caplacizumab treatment for acquired thrombotic thrombocytopenic purpura. N Eng/ J Med 2019;380:335-46.

Copyright 2022 BMJ Publishing Group. All rights reserved. For permission to reuse any of this content visit

https://www.bmj.com/company/products-services/rights-and-licensing/permissions/

BMJ Case Report Fellows may re-use this article for personal use and teaching without any further permission.

Become a Fellow of BMJ Case Reports today and you can:

- Submit as many cases as you like

- Enjoy fast sympathetic peer review and rapid publication of accepted articles

- Access all the published articles

- Re-use any of the published material for personal use and teaching without further permission

\section{Customer Service}

If you have any further queries about your subscription, please contact our customer services team on +44 (0) 2071111105 or via email at support@bmj.com.

Visit casereports.bmj.com for more articles like this and to become a Fellow 